\title{
Qualidade da atenção ao aborto no Sistema Único de Saúde do Nordeste brasilei ro: o que dizem as mulheres?
}

\author{
Quality of abortion care in the Unified Health System \\ of N ortheastern Brazil: what do women say?
}

\author{
Estela M. L. Aquino ${ }^{1}$ \\ Greice $M$ enezes ${ }^{1}$ \\ TháliaVelho Barreto-de-Araújo ${ }^{2}$ \\ Maria Teresa Alves ${ }^{3}$ \\ Sandra Valongueiro Alves ${ }^{2}$ \\ $\mathrm{M}$ aria da Concei ção Chagas de AImei da ${ }^{4}$ \\ Eleonora Schiavo ${ }^{1}$ \\ Luci Praciano Lima ${ }^{2}$ \\ Carlos Augusto Santos de M enezes ${ }^{5}$ \\ Lilian Fátima Barbosa $\mathrm{M}$ arinho ${ }^{6}$ \\ Liberata Campos Coimbra ${ }^{3}$ \\ Oona Campbell ${ }^{7}$
}

${ }^{1}$ MUSA - Programa Integrado em Gênero e Saúde, Instituto deSaúde Coletiva, Universidade Federal da Bahia. Rua Basílio da Gama s $/ n^{\circ}$, Campus Universitário do Canela. 40110-040

Salvador BA. estela@ufba.br

2 Programa de Pós-

Graduação em Saúde

Coletiva, Universidade

Federal dePernambuco.

3 Programa de Pós-

Graduação em Saúde

Coletiva, Universidade

Federal do M aranhão.

${ }^{4}$ Centro de Pesquisas

Gonçalo M oniz, Fundação

Oswaldo Cruz.

${ }^{5}$ Departamento de

Ginecologia, Obstetrícia e

Reprodução Humana,

Faculdade de M edicina da

Bahia, UniversidadeFederal

daBahia.

${ }^{6}$ Departamento deCiências

daVida,Universidade do

Estado da Bahia.

${ }^{7}$ D epartment of Infectious

Disease Epidemiology,

Faculty of Epidemiology

and Population $\mathrm{H}$ ealth,

London School of Hygiene

and Tropical Medicine.
Abstract Abortion is a serious health problem in Brazil and complications can be avoided by adequate and timely care. The article evaluates the quality of care given to women admitted for abortion in hospitals operated by the $\mathrm{U}$ nified $\mathrm{H}$ ealth System, in Salvador, Recife and São Luis, the benchmarks being $M$ inistry of $\mathrm{H}$ ealth norms and user satisfaction. The articleanalyzes 2804 women admitted to hospital for abortion complications in 19 hospitals, between August and December 2010. Four dimensions were defined: re ception and guidance; inputs and physical environment; technical quality and continuity of care. Therewas a closer fit to norms on reception and guidance. Social support and the right to information were not well rated in all three cities. The technical quality of care was rated poor. With respect to inputs and physical environment, cleanliness was the least adequate criterion. Continuity of care was the most critical situation in all three cities, due to the lack of scheduled follow-up appointments, information about care available after hospital discharge, the risk of further pregnancy and family planning. Abortion care falls short of that advocated under Brazilian norms and by international agencies. Key words Induced abortion, Evaluating the quality of health care, Reproductive rights, Patient satisfaction
Resumo 0 aborto é grave problema de saúde no Brasil e suas complicações podem ser evitadas por atenção adequada e oportuna. 0 artigo avalia a qualidade da atenção às mulheres admitidas por aborto em hospitais do Sistema Ú nico de Saúde, em Salvador, Recife e São Luís, tendo como referência as normas do M inistério da Saúde e o grau de satisfação das usuárias. Trata-se de inquérito com 2.804 usuárias, internadas por complicações do aborto em 19 hospitais, de agosto a dezembro de2010. Considerou-se4 dimensões- acolhimento eorientação, insumos/ambientefísico, qualidade técnica e continuidade do cuidado desdobradas em critérios e indicadores. A adequação às normas foi maior quanto aos critérios de acolhimento eorientação. 0 apoio social e 0 direito à informação alcançaram valores baixos nas três cidades. A qualidade técnica do cuidado foi mal avaliada. Em insumos e ambiente físico, a limpeza foi o critério menos adequado. A situação é mais crítica na continuidade do cuidado nas 3 cidades, pela falta de consulta agendada de revisão, de informações sobre cuidados após alta hospitalar, risco de gravidez e planejamento familiar. A atenção ao aborto nessas cidades encontra-sedistante do que propõem as normas brasileiras e os organismos internacionais.

Palavras-chave Aborto induzido, Avaliação da qualidade da atenção à saúde, Direitos reprodutivos, Satisfação de pacientes 


\section{Introdução}

O aborto é grave problema de saúde pública no Brasil pela magnitude da sua ocorrência e pelas complicações à saúde, que chegam a ocasionar a morte, e podem ser evitadas por atenção adequada e oportuna ${ }^{1}$. Por ser permitido apenas quando a gravidez resulta de estupro ou constitui ameaça à vida da mulher, é realizado frequentemente de modo inseguro, gerando hospitalizações desnecessárias e representando riscos à saúde.

Em 2010, em inquérito nacional em áreas urbanas $22 \%$ das mulheres de 35 a 39 anos declararam já ter provocado um aborto ${ }^{2}$. No mesmo ano, registraram-se no país 220.571 internações por complicações do aborto. Na única pesquisa de abrangência nacional ${ }^{3}$, realizada em 2002, nas capitais brasileiras e no Distrito Federal, evidenciou-se que $11,4 \%$ dos óbitos maternos foram devidos a complicações de abortos. Entretanto, existe o reconhecimento de serem estas as causas mais mal declaradas 4 .

A severidade das complicações, embora de terminada pelas condições deocorrência do aborto, depende em larga medida da atenção prestada nos serviços de saúde ${ }^{1,5}$.

São constantes as denúncias do movimento de mulheres acerca de problemas enfrentados pelas usuárias de serviços de saúde, incluindo desde a dificuldade de acesso a uma vaga até situações de discriminação sofridas durante a internação. Esses problemas foram evidenciados em pesquisas qualitativas, realizadas em serviços públicos por profissionais de saúde, principalmente enfermeiras, mas ainda são insuficientes os estudos sobre a qualidade da aten ção recebida nos hospitais pelas mulheres que abortam 4 .

A avaliação da qualidade da atenção inclui como importante componente a satisfação de usuários ${ }^{6}$. Os estudos nacionais sobre satisfação tornaram-semais comuns a partir de 1990, como decorrência das lutas pela democratização que consolidaram direitos à saúde na Constituição de19887. N esta década, cresceu o movimento pela humanização dos serviços de saúde, que tem como elementos centrais o respeito aos direitos dos usuários e consequentemente a satisfação destes com a assistência prestada7.

Em 2005, o M inistério da Saúde lançou a publicação "Atenção Humanizada ao Abortamento: norma técnica" ${ }^{8}$, que define como elementos essenciais do modelo de atenção: 0 acolhimento e a orientação, a atenção clínica ao abortamento e o planejamento reprodutivo pós-abortamento. Entretanto, após quase uma década, não fo- ram realizados estudos que avaliassem em que medida estas normas, que foram reeditadas em 2010, estão sendo cumpridas no Sistema Único deSaúde(SUS).

Este estudo se insere na pesquisa GravSusNE que teve entre seus objetivos avaliar a qualidade da atenção prestada às mulheres admitidas por complicações do aborto em hospitais públicos do Sistema Único de Saúde (SUS), comparando três cidades da região Nordeste - Salvador, Recife e São Luís. A pesquisa inclui estraté gias qualitativas e quantitativas, mas no presente artigo serão apresentados os resultados do inquérito de usuárias, com o propósito de analisar a adequação às normas técnicas relativas à atenção ao aborto inseguro e o grau de satisfação com o cuidado recebido durante internação em decorrência da prática ou de suas complicações.

\section{Métodos}

Trata-se de estudo transversal, onde foram entrevistadas mulheres com 18 anos e mais, residentes no município ondefoi desenvolvido o estudo, internadas com quadros de abortamento ou complicações dele decorrentes, independente da gravidade do quadro clínico apresentado e do tipo de aborto (espontâneo ou provocado). Foram inelegíveis os casos de aborto previsto em lei; os de gravidez ectópica e mola hidatiforme; e aborto resultante de outros produtos anormais da concepção.

O tamanho da amostra foi calculado em 2.562 mulheres para estimar a prevalência das complicações graves e seus fatores de risco, de modo comparativo entre as cidades. Com base na literatura ${ }^{9} \mathrm{e}$ em dados secundários prévios das cidades, assumiu-se uma diferença de $100 \%$ na prevalência de complicações graves de Salvador $(p 2=0,08)$ em relação à prevalência de Recife ( $\mathrm{p} 1=0,04)$. Para al cançar o tamanho de amostra, foi efetuado censo de mulheres elegíveis, internadas de 31 deagosto a 30 de dezembro de2010, em sete hospitais de Salvador, oito de Recife e quatro de São Luís. Foram incluídos todos os hospitais públicos com internações por abortamento (exceto um em Salvador e dois em São Luís que tiveram menos de 120 internações em 2007).

Sal vador conta com cinco maternidades edois hospitais gerais com atenção obstétrica (um estabelecimento federal e seis estaduais, um deles gerido por entidade filantrópica); ao todo, são seis unidades de média complexidade e um hospital geral dealta complexidade. Q uatro são uni- 
dades de ensino e duas dispõem de Unidade de Tratamento Intensivo (UTI). Há um único serviço de aborto nos casos previstos por lei.

Recife possui uma rede com três unidades municipais, duas estaduais e três hospitais escola; quatro são unidades de alta, uma de média e três de baixa complexidade. Cinco estabelecimentos funcionam como unidades de ensino, sendo que quatro possuem UTI. Há sete serviços de atenção ao aborto previsto por lei.

Em São Luís, das quatro unidades integrantes do estudo umaéfederal, duas estaduais euma filantrópica contratada; do total, três são unidades de alta complexidade e uma de média. Em todas há atividades de ensino. Um hospital geral e uma maternidade dispõem de UTI. A cidade conta com um único serviço de aborto legal.

Para avaliar a adequação às normas de atenção humanizada ao aborto, foram consultados documentos oficiais que compõem o quadro ético-normativo da atenção às mulheres e ao abortamento em particular8,10-12, além de literatura científica sobre avaliação em saúde, na perspectiva de usuárias ${ }^{7}$. Entretanto, estes textos não definem metas que possam ser quantificadas ou parâmetros para avaliar a adequação do cuidado. Com o apoio destes documentos, foram definidas quatro dimensões, com respectivos critérios e indicadores, a serem avaliados:

a) Acolhimento eorientação - orientada pelo conceito de humanização e de garantia de direitos humanos, édefinida como "o tratamento digno e respeitoso, a escuta, o reconhecimento e a aceitação das diferenças, o respeito ao direito de decidir de homens e mulheres" ${ }^{8}$, e neste estudo inclui seis critérios - agilidade no atendimento, respeito às mulheres usuárias, privacidade na atenção, aceitação de diferenças (ou não discriminação), apoio social, direito à informação sobre procedimentos a que são submetidas;

b) Qualidade técnica do cuidado - é entendida neste estudo como a aplicação apropriada de conhecimento médico e tecnologia disponível, transformando recursos em resultados ${ }^{13}$. Inclui: tipo de procedimento de esvaziamento uterino, alívio da dor, examefísico pós-esvaziamento uterino, controle da pressão arterial e da temperatura;

c) Insumos/ambiente físico: incluindo dois critérios relativos ao ambiente (limpeza do espaço físico e troca da roupa de cama) e dois de cuidados pessoais (roupa da usuária e absorventes);

d) Continuidade do cuidado: éorientada pelo princípio de integralidade da atenção, definida na Lei N o. $8080^{14}$ como "conjunto articulado e contínuo das ações e serviços, preventivos e cu- rativos". Inclui como critérios: orientações sobre cuidados após a alta, agendamento de consulta de revisão, acesso a informações e insumos para 0 adequado planejamento reprodutivo.

A Figura 1 apresenta dimensões, critérios e indicadores, os quais orientaram a seleção e a elaboração de questões a serem aplicadas nas usuárias. 0 módulo sobre qualidade da atenção do questionário contemplou os diferentes momentos assistenciais: antes, durantee após o procedimento deesvaziamento uterino; atenção pósalta eimpressões gerais sobreo atendimento, estes dois últimos necessariamente aplicados após a alta médica. Este módulo foi em grande parte adaptado de instrumento da O rganização M undial de Saúde ${ }^{15}$, incluindo tradução e retradução inglês-português, demodo independentee avaliação da equivalência semântica. Foram também adaptadas questões relativas a impressões gerais sobre 0 atendimento do questionário individual da Pesquisa Mundial de Saúde ${ }^{16}$ e elaboradas questões complementares sobre privacidade, tratamento da dor, presença de acompanhante, qualidadetécnica do cuidado etipo de procedimento para esvaziamento uterino, de modo a cobrir o espectro de critérios al mejado.

Os dados foram obtidos por meio de entrevistas face a face para aplicação de questionário estruturado e pré testado, com a realização posterior de estudo piloto com 52 mulheres internadas em 13 hospitais da rede SU S dos três centros. As entrevistas foram realizadas nos períodos da manhã e da tarde, nos sete dias da semana, inclusive feriados. A equipe de entrevistadoras, especialmente treinadas para este fim, foi composta por mulheres profissionais de saúde de nível superior protegidas pelo sigilo profissional. 0 controle de qualidade incluiu a revisão de todos os questionários pelas supervisoras; reuniões semanais da equipe; supervisão nos hospitais para observação direta das entrevistas; comparação do número de el egíveis identificadas no trabalho de campo com o número de Autorizações de Internação H ospitalar (AIH) por abortamento nas maternidades selecionadas, durante o mesmo período, e registradas no SIH/DATASUS, segundo os mesmos critérios.

Foram utilizados os softwares EPI INFO for Windows para constituir a base de dados eo Stata/ SE 10.0 for Windows para análises estatísticas.

Os indicadores correspondentes a cada um dos critérios foram expressos sob a forma de proporção, considerando-se 1,0 como padrão ideal. Não havendo nas normas parâmetros que orientassem a avaliação de adequação, adotou- 


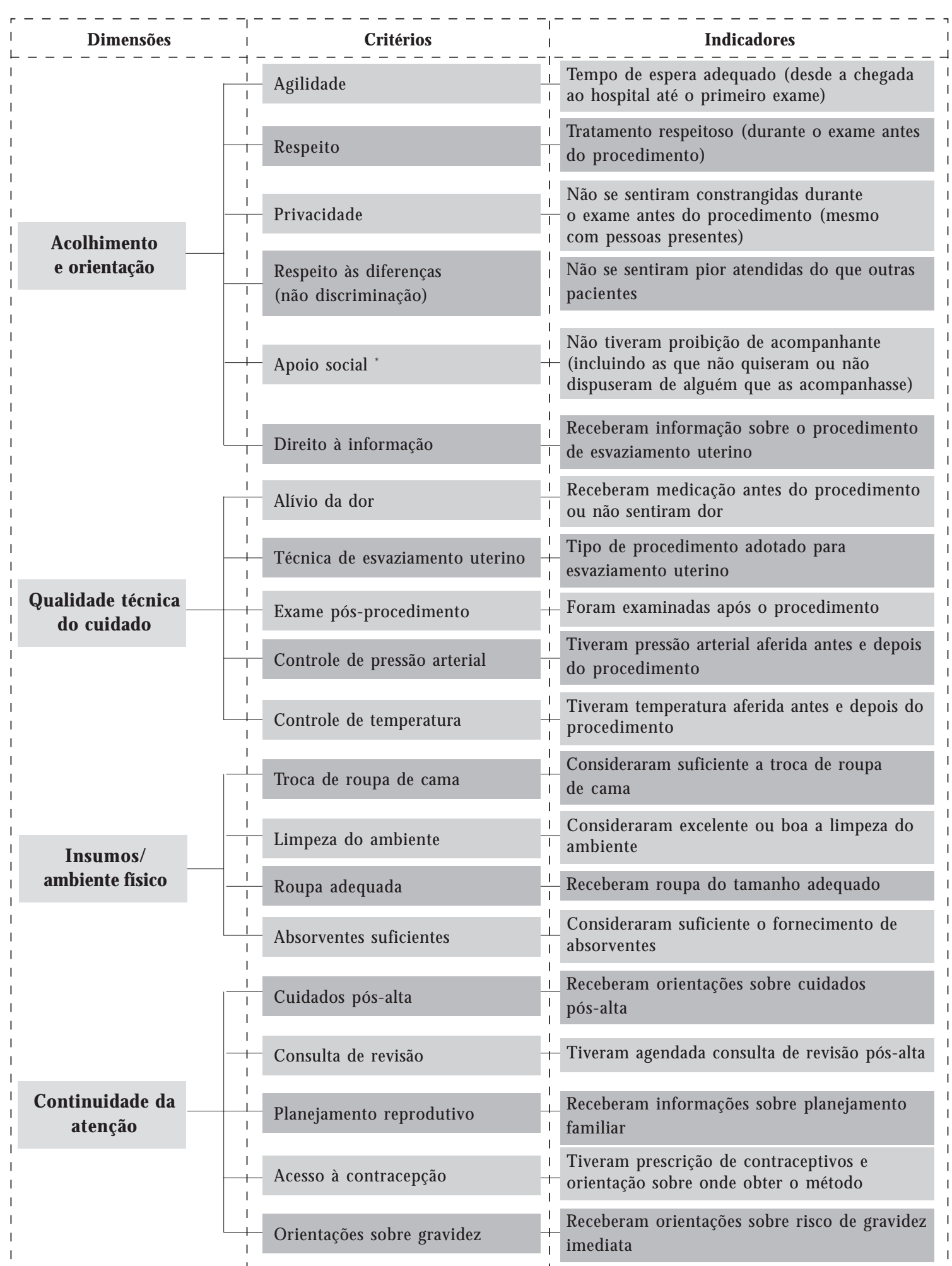

Figura 1. Dimensões, critérios e indicadores de adequação às normas de atenção humanizada ao abortamento

Fontes: Brasil| ${ }^{8}$; OM S12,16.

*A presença de acompanhantenão está prevista nas normas de atenção ao aborto, sendo um direito das mulheres no parto 
senesteestudo a divisão em quartis: até 0,25 (pior situação); 0,26-0,50; 0,51-0,75; 0,76-1,00 (melhor situação). Para testar a significância estatística das diferenças entre as cidades foi utilizado o teste de qui-quadrado de Pearson.

Foi construído um gráfico de radar para re presentar os resultados, onde cada dimensão é representada num eixo próprio, irradiado a partir do ponto central, em queo menor valor ézero e avançando em direção à extremidade do eixo em queo valor é100. Estepermite, considerando as quatro dimensões, verificar e comparar as três cidades quanto aos critérios de adequação.

A satisfação das usuárias com a aten ção prestada foi apreendida com a questão "Você considera que foi atendida satisfatoriamente?", e as respostas estimuladas segundo as seguintes alternativas: sempre que precisou; parte das vezes; nunca. Os resultados foram apresentados em gráfico de barras comparando as três cidades.

Os princípios éticos de respeito à pessoa, be neficência ejustiça foram assegurados. As entrevistas foram feitas com as mulheres já em boas condições físicas, em momentos em que aguardavam a saída do hospital, na maioria dos casos, quando já lhes havia sido comunicada a alta médica. Foram realizadas em locais próprios ou nas enfermarias, onde estivessem asseguradas condições mínimas de privacidade. Considerando o contexto de ilegalidade, ao invés de constranger as entrevistadas a assinarem um documento, o registro da anuência em participar da pesquisa foi assegurado por Termo de Consentimento Verbal lido para todas as entrevistadas e assinado pelas entrevistadoras. Foram assegurados os direitos à interrupção da entrevista, recusa a perguntas específicas e desistência de participação. 0 projeto foi aprovado pelos Comitês de Ética das três universidades e pelo CONEP. Em dois estabelecimentos foi exigida a submissão aos comitês hospitalares - Comitê de Ética da M aternidade Climério de Oliveira (UFBa) e Comitê de Ética do Instituto de M edicina Integral Prof. Fernando Figueira(IMIP) - Recife/PE.

\section{Resultados}

De 30 de agosto a 31 de dezembro foram entrevistadas 2.804 mulheres nos 19 estabelecimentos hospitalares (1.652 em Salvador, 391 em Recife e 761 em São Luís), registrando-se no total 5,8\% de perdas e $2,7 \%$ de recusas. Pequeno percentual das mulheres $(5,1 \%)$ não respondeu às questões sobre insumos/ ambiente físico e continuidade da atenção, pois estas conformavam bloco a ser obrigatoriamenterespondido após comunicação da alta à paciente.

A idade mediana das entrevistadas foi de 27 anos, sendo estas $50,4 \%$ pardas e $33,8 \%$ pretas. $M$ ais da metade $(57,0 \%)$ completou o ensino médio. Para $23,8 \%$ aquela era a primeira gravidez; 10,9\% embora com gestação anterior não possuíam filhos e $71,2 \%$ tinham até dois; $35,2 \%$ mencionaram um aborto anterior, dos quais $45,8 \%$ foram declarados como provocados (dados não apresentados).

Sem diferenças expressivas entre as cidades, grande parte das entrevistadas considerou adequado o tempo de espera desde a chegada ao hospital até o primeiro atendimento e a quase totalidade definiu como respeitoso o tratamento recebido durante 0 exame antes do esvaziamento uterino (Tabela 1).

Em relação à privacidade, as mulheres declararam não ter sentido constrangimento pela presença de pessoas durante $o$ exame pré-procedimento (pouco menos de um terço afirmaram não ter ninguém presente) e as diferenças não foram estatisticamente significantes entre as cidades (Tabela 1). Quando havia pessoas presentes, eram profissionais de saúde (87,5\%) e eventual mente outras pacientes e seus acompanhantes (dados não apresentados).

Nas três cidades, maioria absoluta das muIheres afirmou não ter sido pior atendida do que as demais pacientes (Tabela 1). Ainda assim, 235 mulheres ( $8,9 \%$ do total) declararam sentir-se discriminadas, dentre as quais $67,6 \%$ em razão da suspeita ou certeza de que o aborto foi provocado (dados não apresentados).

Frequentemente, as mulheres não tiveram assegurado o direito à informação sobre o procedimento de esvaziamento uterino (Tabela 1). Recife apresentou situação um pouco maisfavorável, já que metade das entrevistadas declarou ter sido informada; no outro extremo esteve São Luís, com menos de um terço, ficando Salvador em posição intermediária.

A situação nas três cidades diferiu muito ao se anal isar a permissão dos estabel ecimentos para ter acompanhante durante a internação, que foi mencionada pela grande mai oria das entrevistadas em Recife $(86,2 \%)$, pouco mais da metade em Salvador e menos de um terço em São Luís (28,8\%) (Tabela 1).

Em relação ao alívio da dor antes do procedimento, Recife apresentou melhor situação e São Luís a pior, mas nas três cidades uma proporção alta de mulheres não recebeu analgesia (Tabela 
Tabela 1. Indicadores de adequação às normas de atenção humanizada ao aborto por cidade - Salvador, Recife e São Luís, 2010

\begin{tabular}{|c|c|c|c|c|}
\hline Indicador & Salvador & Recife & São Luís & p-valor \\
\hline Tempo de espera adequado (desde a chegada ao hospital até o primeiro exame) & 72,4 & 75,7 & 79,0 & 0,002 \\
\hline Tratamento respeitoso (durante o exame antes do procedimento) & 90,7 & 93,8 & 94,0 & 0,008 \\
\hline $\begin{array}{l}\text { Não se sentiram constrangidas durante o exame antes do procedimento } \\
\text { (mesmo com pessoas presentes) }\end{array}$ & 87,0 & 86,2 & 89,4 & 0,484 \\
\hline Receberam informação sobre o procedimento de esvaziamento uterino & 37,1 & 50,5 & 28,8 & 0,000 \\
\hline Não se sentiram pior atendidas do que outras pacientes & 90,5 & 94,3 & 90,8 & 0,068 \\
\hline Presença de acompanhante permitida & 50,8 & 86,2 & 28,8 & 0,000 \\
\hline Alívio da dor antes do procedimento (ou não sentiram dor) & 69,5 & 60,9 & 52,2 & 0,000 \\
\hline Examinadas após o procedimento & 64,2 & 65,4 & 23,3 & 0,000 \\
\hline Pressão arterial aferida antes e depois do procedimento & 80,5 & 88,7 & 31,7 & 0,000 \\
\hline Temperatura aferida antes e depois do procedimento & 69,7 & 43,8 & 4,4 & 0,000 \\
\hline Troca de roupa de cama suficiente & 69,7 & 53,9 & 39,8 & 0,000 \\
\hline Limpeza do ambiente excelente ou boa & 54,0 & 56,7 & 46,6 & 0,001 \\
\hline Roupa do tamanho adequado & 67,1 & 61,2 & 58,9 & 0,000 \\
\hline Fornecimento suficiente de absorventes & 88,2 & 63,0 & 19,6 & 0,000 \\
\hline Receberam orientação sobre cuidados pós-alta & 35,0 & 51,7 & 20,0 & 0,000 \\
\hline Tiveram agendada consulta de revisão pós-alta & 5,2 & 27,8 & 4,3 & 0,000 \\
\hline Receberam informações sobre planejamento familiar & 35,5 & 25,6 & 3,2 & 0,000 \\
\hline Contraceptivos prescritos com orientação sobre onde obtêlos & 14,7 & 7,9 & 1,1 & 0,000 \\
\hline Receberam orientações sobre risco de gravidez imediata & 37,5 & 44,4 & 9,9 & 0,000 \\
\hline
\end{tabular}

\begin{tabular}{|c|c|c|}
\hline $76-100 \%$ & $51-75 \%$ & \\
\hline
\end{tabular}

1). Embora em termos proporcionais não che gue a $2 \%$, cabe destacar por refletir a baixa qualidade técnica que 49 mulheres (das quais $31 \mathrm{em}$ São Luis) relataram ter sentido dor durante a curetagem (dados não apresentados).

A realização de exame após o procedimento, permitindo a avaliação do volume e aspecto do sangramento, correspondeu a $64,2 \%$ em Salvador e $65,4 \%$ em Recife, mas foi bem menos frequente em São Luís (23,3\%) (Tabela 1). A aferição de pressão arterial foi muito frequente em Salvador e Recife (respectivamente $80,5 \%$ e $88,7 \%)$, mas muito insuficiente (31,7\%) em São Luís. Pior a adequação, quando se considera 0 controle da temperatura, portanto de prevenção de complicações infecciosas: em Salvador esta medida foi efetuada antes e depois do procedimento em $69,7 \%$ das mulheres, enquanto em Recife isto ocorreu bem menos ( $43,8 \%$ ) eem São Luísfoi praticamenteinexistente $(4,4 \%)$.

$\mathrm{N}$ a avaliação de aspectos do ambiente físico e da oferta deinsumos durantea internação, constata-se certa proximidade entre as respostas das entrevistadas de Salvador e Recife, com mais da metade delas informando ter sido suficiente a troca de roupa e o fornecimento de absorventes; ter recebido roupa do tamanho adequado, além deter sido excelenteou boaa limpezado ambiente. Em São Luis, a avaliação foi menos positiva para todos os indicadores com os mais baixos val ores para a troca de roupa de cama e o fornecimento de absorventes (Tabela 1).

Indicadores relativos à continuidade da atenção figuram entre aqueles que receberam a pior avaliação, mais uma vez ressaltando a pior situação informada pelas entrevistadas em São Luís. Ali, 20\% das mulheres mencionaram ter recebido orientação sobre cuidados a serem seguidos após a alta hospitalar, menos de 10\% terem sido alertadas sobre o risco de gravidez imediata e menos de $5 \%$ delas terem sido agendadas para consulta de revisão. Só 3,2\% das entrevistadas desta cidade informaram ter recebido orientações sobre planejamento familiar e para apenas $1,1 \%$ delas, foram prescritos contraceptivos com orientação de locais para sua obtenção. Contudo a situação em Recife e Salvador não é muito melhor, com praticamente todos os indicadores das duas cidades estando abaixo de $50 \%$; eainda que as pernambucanas tenham sido um pouco mais frequentemente orientadas sobre cuidados pós-alta e sobre risco de gravidez, e agendadas 
para consulta de revisão, as baianas declararam mais ter recebido informações sobre contracepção pós-aborto, com prescrição de métodos e orientação de como obtêlos (Tabela 1).

Considerando-se as quatro dimensões avaliadas (Gráfico 1), confirma-se que nas três cidades há uma maior adequação às normas quanto aos critérios de "acolhimento eorientação", especialmente quanto à agilidade, respeito, privacidade e não discriminação. Ainda assim, os crité rios de apoio social e direito à informação tiveram valores baixos nas três cidades. A "qualidade técnica do cuidado" é mais mal avaliada, despontando o controle da temperatura e o exame pós-procedimento com menor adequação. Em "insumos e ambiente físico" destaca-se a limpeza do ambiente como o critério menos adequado. Mas éa "continuidade do cuidado" que apresenta a situação mais crítica em todas as cidades (Gráfico 1).

Quanto à satisfação com o atendimento, dois terços das mulheres em Salvador e Recife, emais da metade delas em São Luís manifestaram-se satisfeitas com 0 atendimento recebido sempre que precisaram. Ainda assim, proporção expressiva das usuárias, especialmenteem São Luís não se sentiu satisfeita ao menos em parte das vezes que precisou (Gráfico 2).

\section{Discussão}

A qualidade da atenção ao aborto no Brasil ainda épouco avaliada ${ }^{17}$ eesteestudo pretendeu pre encher esta lacuna investigando o tema, a partir da perspectiva das usuárias.

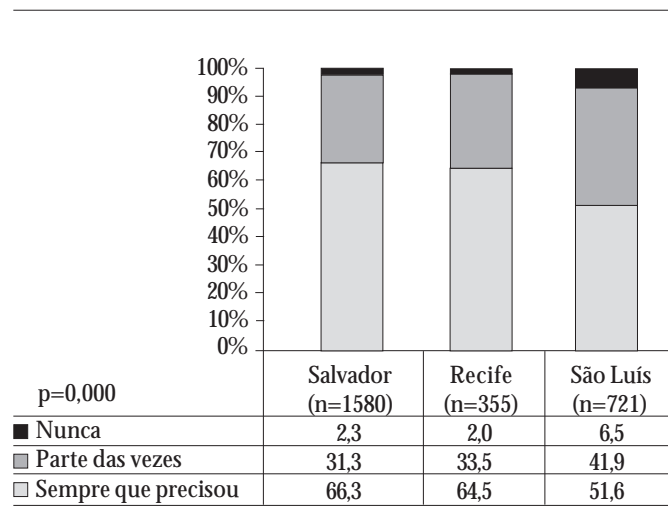

Gráfico 2. Satisfação* de mulheres internadas por complicações de aborto com 0 atendimento prestado, segundo cidade - Salvador, Recife e São Luís - 2010

* “vocêconsidera quefoi atendida satisfatoriamente?"

Continuidade do cuidado

Acolhimento e orientação

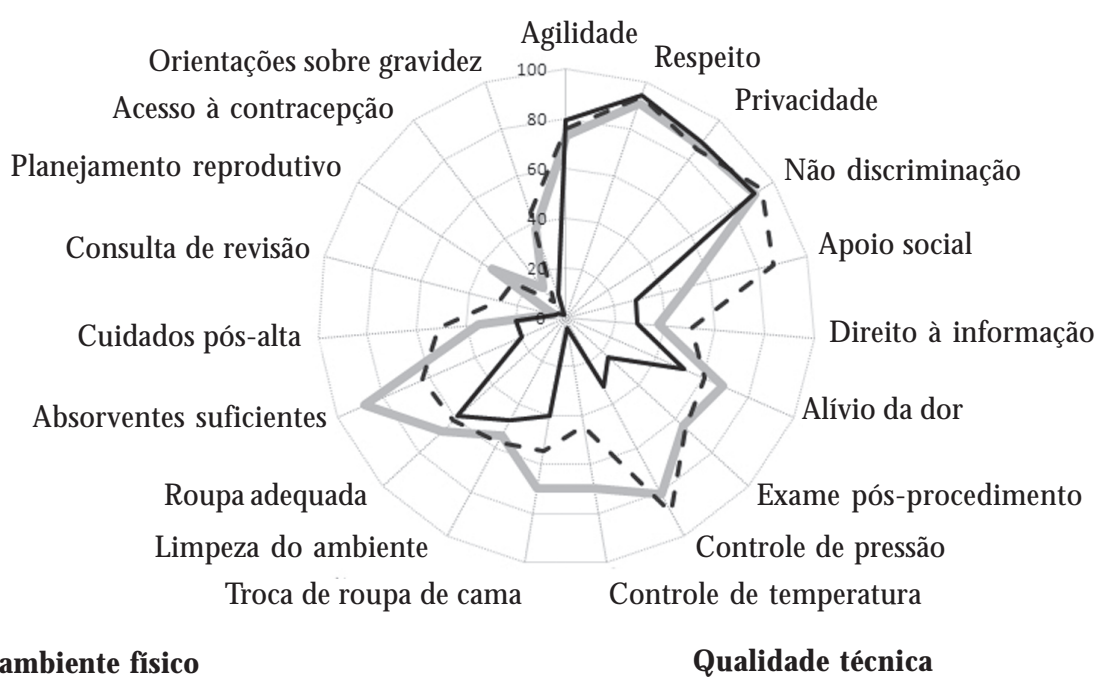

— Salvador _ - Recife _ São Luís 
Foram alcançadas altas taxas de resposta e os cuidadostomados propiciaram proporções reduzidas de perdas erecusas, especialmentena medida em que aumentou a experiência da equipe em lidar com os inúmeros desafios da pesquisa.

A decisão deconsiderar elegíveis mulheres em situação de abortamento, independentementese o foi ou não provocado, baseou-se na compreensão de que, em contextos de ilegalidade, muitos abortos provocados são declarados como espontâneos e sua exclusão pode levar à subestimação dos primeiros e ao obscurecimento dos fenômenos deinteresse ${ }^{18}$. Ademais, mesmo aquelas com abortos espontâneos estão expostas a situações de discriminação pela mera suspeita de que estes foram induzidos.

Os resultados tornaram evidente que a atenção ao aborto, ao menos nas três cidades investigadas, encontra-se bem distante do que propõem as normas brasileiras e os organismos internacionais, incluindo os acordos assumidos pelo governo brasileiro.

Observou-se ênfase na dimensão curativa do cuidado com absoluta negligencia das práticas preventivas, e das que reforçam a autonomia das mulheres no processo de decisão sobre a reprodução. Em relação ao acesso à contracepção, o quadro encontrado nas três cidades é semel hante ao de outros países latino-americanos onde o aborto é ilegal, sobretudo antes da adoção de estratégias de intervenção para mel horia da qualidade do cuidado ${ }^{19}$.

A informação para as mulheres sobre o procedimento que será realizado ocorre poucas vezes e em frequência muito inferior ao que se observa em estudos sobre cesárea, onde a maioria das mulheres é informada sobre a escolha do procedimento cirúrgico no parto ${ }^{20}$.

0 manejo da dor por métodos farmacológicos deixa muito a desejar, o que tem sérias implicações humanitárias ao impor às mulheres inaceitáveis sofrimento, ansiedade e desconforto, com potencial risco para a saúde ${ }^{12}$.

Como observado em outros países da Amé rica Latina ${ }^{19}$, a curetagem foi a técnica adotada na quase totalidade dos casos, reproduzindo um modelo tradicional que requer anestesia ou sedação profunda, admissão hospitalar, mais longa espera pelo tratamento e permanência por pelo menos 24 horas. Além disso, há maiores riscos de complicações, especialmente quanto mais avançada a gravidez, contrariando o princípio da beneficência e as recomendações nacionais ${ }^{8}$ e internacionais $s^{12,15}$. Na perspectiva da humanização da atenção, a manutenção do modelo fere o princí- pio da integridadefísica eo propósito de eliminação ou redução de procedimentos não recomendados com base em evidências científicas, ${ }^{8,21}$.

A presença de acompanhante é direito das mulheres durante o trabalho de parto ${ }^{22}$, com regulamentação no âmbito do SUS. Nos casos de aborto tal permissão fica a critério de políticas locais ou dos gestores das unidades de saúde. M esmo na situação de parto é pouco frequentea concretização desse direito ${ }^{23}$. A falta de privacidade e a inadequação arquitetônica das enfermarias servem como justificativa para que alguns estabelecimentos, quando admitem a presença de acompanhante, limitem-na a pessoas do sexo feminino ${ }^{20}$. Outra forte justificativa já evidenciada para essa interdição é a possibilidade de maior questionamento e demandas, além da vigilância das práticas dos profissionai $\varsigma^{20}$.

A incorporação desse direito na atenção ao aborto possivelmente encontra maior resistência pelos profissionais e instituições, pois se há evidências de queo suporte social contribui para a evolução positiva do trabalho de parto e do parto e para a redução da ocorrência de complicações ${ }^{24,25}$, nos casos do aborto este papel é menos evidente dado a pouca valorização no modelo assistencial vigente de aspectos psicossociais e a escassez de pesquisas sobre o tema ${ }^{26}$.

A baixa frequência de relatos de discriminação deve ser analisada com ressalvas, já que se trata de fenômeno delicado e complexo, e sua apreensão por meio de perguntas fechadas pode ser mais difícil a depen der do contexto de realização. M aus tratos e desumanização da atenção foram bem documentados em pesquisas com observação participante eentrevistas em profundidade demulheresinternadas em maternidades públicas, sobretudo no nordeste do paí s7 ${ }^{27}$. A discriminação é também simbólica, institucionalizada na estrutura física, na forma de organização do atendimento, na destinação dos espaços reservados às mulheres, no adiamento da realização das curetagens para os horários finais dos plantões. As demandas das mulheres que abortam são consideradas ilegítimas nas maternidades, espaços destinados ao atendimento das parturientes ${ }^{27-30}$.

Mulherescom experiências deinternaçõesanteriores têm expectativas de que serão mal tratadas por terem abortado. Quando episódios específicos não se confirmam, elas tendem a avaliar positivamente $a$ atenção, privilegiando o restabelecimento da saúdefísica ea possibilidade de retomada da vida cotidiana, sobretudo considerando o longo percurso que muitas vivenciaram 
até a concretização do aborto e a internação no hospital 27,30,31.

Deve ser ressaltada a precariedade dos indicadores de continuidade do cuidado nas três cidades, que apontam na direção oposta da integralidade ${ }^{32}$. A orientação sobrecuidados pós-alta e o agendamento de consulta de revisão permitiriam evitar complicações imediatas à saúde das mulheres, mas sobretudo a orientação e a prescrição da contracepção pós-aborto propiciariam a não reincidência do aborto.

Os resultados do presente estudo convergem com aqueles de pesquisas anteriores ${ }^{27-31,33}$, quanto à impessoalidade da atenção e à falta de informações sobre as intervenções a serem realizadas, sem considerar as necessidades das mulheres e a sua capacidadedecompartilhar decisões, tal como preveem as normas 8 .

Estes aspectos também estão presentes na atenção ao parto, indicando a necessidade deum questionamento maior sobre a atenção obstétrica prestada na rede pública no Brasil. Traduzem práticas de violência institucional ${ }^{34,35}$, com contornos específicos na atenção ao abortamento, face às posturas dos profissionais de julgamento e punição das mulheres pelo aborto ${ }^{36}$.

M erece ser comentado que os indicadores de qualidade, construídos a partir da percepção das mulheres sobre a atenção recebida, foram obtidos em ambiente hospitalar, após a realização de curetagem e a alta médica, imediatamente antes de deixar a unidade. Portanto, a qualidade da informação depende além da memória que é seletiva efortemente influenciada pelas condições de rememoraçãa $0^{7,19}$, mas também da baixa expectativa das usuárias com 0 atendimento em unidades de saúde, especialmente quando acabaram deconcluir sem complicações um processo complexo, com grande carga emocional ${ }^{31}$. M esmo com os cuidados adotados pela equipe, identificando-se como pesquisadoras da universidade e assegurando sigilo e confidencialidade das respostas, não se pode afastar que muitas tenham temido retaliações por emitirem eventuais opiniões mais críticas sobre a assistência. Em estudo anterior ${ }^{34}$, parturientes entrevistadas fora do espaço do hospital demonstraram mais segurança para criticarem a atenção recebida.

Para contornar estes limites, optou-se sempreque possível por solicitar informações fatuais emais objetivas, tais como a realização detecnologias debaixa densidadee conhecimento universalmente disseminado como aferição de temperatura corporal e pressão arterial ou o tipo de procedimento para o esvaziamento uterino realizado.
Há que se ter cautela na interpretação dos resultados que envolvem grande subjetividade como a avaliação do tratamento como respeitoso ou sobre a adequação do tempo de espera, os quais foram exatamente aqueles melhor avaliados. M as não há como deixar de considerar a percepção de usuários na avaliação dos serviços, especialmente no que diz respeito às relações interpessoais e à humanização da atençãa?

As condições de produção das entrevistas devem ser especialmenteconsideradas quanto ao chamado ef eito de "gratitude bias" 7 que influenciaria as respostas sobre satisfação, que também dependem de característicastais como idade, classe social, estado psicológico, experiência prévia com os serviços de saúde, papel atribuído aos serviços. Autores chamam a atenção de que o sistema pode ser menos responsivo exatamente com aqueles que "aprenderam" a ter menos expectativas ea exercer sua capacidadecrítica ${ }^{7}$. Com as dificuldades habituais de acesso aos serviços, o fato de ser atendido e, no caso do aborto, ter seu problema de saúde resolvido pode resultar em maior satisfação sem que isso represente a adequada aplicação das normas e a maior qualidade da atenção.

A estrutura e a organização das unidades são distintas nas três cidades e podem explicar as diferenças encontradas neste estudo. Devem ser objeto de análise com o aprofundamento do estudo e a triangulação com os dados qual itativos da mesma pesquisa.

As normas de atenção humanizada ao aborto constituem um avanço na medida em que definem a forma de organização da atenção ao abortamento e conformam racionalidade indicativa de suas atividades estruturantes. Contudo, as normas precisam ser aperfeiçoadas com 0 estabelecimento de parâmetros mínimos de adequação eindicadores de avaliação, tal como existe para atenção ao pré natal e ao parto ${ }^{21}$.

No âmbito deste estudo, foi efetuado esforço para detalhar conjunto mínimo de indicadores e, ao menos provisoriamente, propor critérios estatísticos de ad equação. Esta estratégia de análise estatística é limitada, no sentido de que dificilmente pode ser aplicada a todos os critérios que foram utilizados neste estudo. Exemplo disso éo alivio da dor, já queéinaceitável que qualquer mulher esteja exposta a este sofrimento sem receber cuidado e, portanto, o não cumprimento desteprocedimento devese constituir em evento-sentinela da qualidade da atenção. Ao evidenciar a frequência dos indicadores selecionados, pretendeu-se contribuir para essa discussão e 
embasar a elaboração de parâmetros de qualidade para a atenção ao abortamento, passíveis de serem medidos no cotidiano dos serviços.

A avaliação deve ser entendida como ferramenta para tomada de decisões ${ }^{37}$. No Brasil, assim como em outros países ondenão setem acesso ao aborto seguro, a atenção pós-aborto deve no mínimo salvar vidas e criar oportunidades para prevenir futuras gravidezes não pretendidas com o acesso a aconselhamento e insumos para o planejamento reprodutivo ${ }^{19}$. Devem ser honrados os compromissos internacionais assumidos pelo Governo Brasileiro de envidar esforços para assegurar o acesso à atenção ao aborto com qualidade, de modo a preservar a saúde e os direitos reprodutivos das mulheres.

\section{Colaboradores}

EM L Aquino, G M enezes, TV Barreto-de-Araújo, M T Alves, SV Alves, E Schiavo eLP Lima participaram de todas as etapas desde a concepção, análise einterpretação dos dados, redação eaprovação do artigo. M CCAlmeida participou da análise einterpretação dos dados, redação eaprovação do artigo. CAS M enezes, L M arinho e LC Coimbra participaram da concepção e desenvolvimento do estudo e revisão crítica do artigo. 0 Campbell participou da revisão crítica eda aprovação do artigo.

\section{Agradecimentos}

Agradecemos à equipe de campo eàs 2.804 usuárias que generosamente concordaram em participar deste estudo contribuindo para a avaliação da qualidade da atenção pós-aborto no Sistema ú nico de Saúde. 


\section{Referências}

1. Grimes DA, Benson J, Singh S, Romero M, Ganatra $\mathrm{B}$, Okonofua FE, Shah IH. Unsafe abortion: the preventable pandemic. Lancet 2006; 368(9550):1908-1919.

2. Diniz D, Medeiros M. Aborto no Brasil: uma pesquisa domiciliar com tecnica de urna. Cien Saude Colet 2010; 15(Supl. 1):959-966.

3. Laurenti R, Jorge MHPdM, Gotlieb SLD. A mortalidade materna nas capitais brasileiras: algumas características e estimativa de um fator de ajuste. Rev Bras Epidemiol 2004; 7(4):449-460.

4. Menezes $G$, Aquino EM. Pesquisa sobre o aborto no Brasil: avanços e desafios para o campo da saúde coletiva. Cad Saude Publica 2009; 25(Supl. 2): S193-204.

5. Sedgh G, Singh S, Shah IH, Ahman E, H enshaw SK, Bankole A. Induced abortion: incidence and trends worldwide from 1995 to 2008. Lancet 2012; 379(9816): 625-632.

6. Donabedian A. Evaluating the quality of medical care. 1966. The M ilbank quarterly 2005; 83(4):691729.

7. Vaitsman J, Andrade GRBd. Satisfação e responsividade: formas de medir a qualidade e a humanização da assistência à saúde. Cien Saude Colet 2005; 10(3):599-613.

8. Brasil. M inistério da Saúde (MS). Secretaria de Atenção à Saúde. Atenção humanizada ao abortamento: norma técnica. $2^{\text {a }}$ ed. Brasília: MS; 2005.

9. Say L, Pattinson RC, Gulmezoglu AM. WHO systematic review of maternal morbidity and mortality: the prevalence of severe acute maternal morbidity (near miss). Reproductive health 2004; 1(1):3.

10. Brasil. M inistério da Saúde (MS). Secretaria de Atenção à Saúde. Política nacional de atenção integral à saúde da mulher: plano de ação 2004-2007. Brasília: MS; 2004. 48 p.

11. Brasil. M inistério da Saúde (MS). Secretaria de Atenção à Saúde. Direitos Sexuais e Direitos Reprodutivos: uma prioridade do governo. Brasília: M S; 2005.

12. Organização Mundial da Saúde. International Women's Health Coalition. Abortamento Seguro: orientação técnica e política para os sistemas da saúde. Campinas: CEM ICAM P; 2004.

13. Lopes RM, Vieira-da-Silva LM, Hartz ZM dA. Teste de uma metodologia para avaliar a organização, acesso e qualidade técnica do cuidado na atenção à diarréia na infância. Cad Saude Publica 2004; 20(Supl. 2):S283-S97.

14. Brasil. M inistério da Saúde. Lei № 8.080 , de 19 de setembro de 1990. Dispõe sobre as condições para a promoção, proteção e recuperação da saúde, a organização e o funcionamento dos serviços correspondentes e dá outras providências. Diário O ficial da União 1990; 20 set.

15. World Health Organization (WHO). Maternal and $\mathrm{H}$ ealth and Safe Motherhood Program. Studying unsafe abortion: a practical guide. Geneva: (WHO); 1996.

16. World Health Organization (WHO). Pesquisa M undial de Saúde. [página na Internet]. [acessado 2012 jun 9]. Disponível em: http://www.who.int/healthinfo/survey/whslongindividuala.pdf
17. Brasil. M inistério da Saúde (MS). Secretaria de Ciência e Tecnologia TelEDdCeT. Aborto e saúde pública no Brasil: 20 anos. Brasília: M S; 2009.

18. Singh S. Hospital admissions resulting from unsafe abortion: estimates from 13 developing countries. Lancet 2006; 368(9550):1887-1892.

19. Billings DL, Benson J. Postabortion care in Latin America: policy and service recommendations from a decade of operations research. Health policy and planning 2005; 20(3):158-166.

20. d'Orsi E, Chor D, Giffin K, Angulo-Tuesta A, Barbosa GP, Gama AdS, Reis AC, Hartz Z. Qualidade da atenção ao parto em maternidades do Rio de Janeiro. Rev Saude Publica 2005; 39(4):645-654.

21. Serruya SJ, Lago TDG, Cecatti JG. O panorama da atenção pré-natal no Brasil e o Programa de Humanização do Pré-natal e Nascimento. Rev. Bras. Saúde M atern. Infant. 2004; 4(3):269-279.

22. Brasil. Lei $\mathrm{N} 011.108$, de 7 de abril de 2005. Altera a Lei no 8.080 , de 19 de setembro de 1990, para garantir às parturientes 0 direito à presença de acompanhante durante o trabalho de parto, parto e pósparto imediato, no âmbito do Sistema Único de Saúde - SUS. Diário Oficial da União 2005; 8 abril.

23. Hotimsky SN, Alvarenga ATD. A definição do acompanhante no parto: uma questão ideológica? Revista Estudos Feministas 2002; 10(2):461-481.

24. Hodnett ED, Gates S, Hofmeyr GJ, Sakala C, Weston J. Continuous support for women during childbirth. Cochrane Database Syst Rev 2011(2): CD 003766.

25. Brüggemann OM, Parpinelli MA, O sis MJD. Evidências sobre o suporte durante o trabalho de parto/parto: uma revisão da literatura. Cad Saude Publica 2005; 21(5):1316-1327.

26. Veiga M B, Lam M, Gemeinhardt C, Houlihan E, Fitzsimmons BP, Hodgson ZG. Social support in the post-abortion recovery room: evidence from patients, support persons and nurses in a Vancouver clinic. Contraception 2011; 83(3):268-273.

27. McCallum C, Reis APd. Re-significando a dor e superando a solidão: experiências do parto entre adolescentes de classes populares atendidas em uma maternidade pública de Salvador, Bahia, Brasil. Cad Saude Publica 2006; 22(7):1483-1491.

28. Motta ISD. A relação interpessoal entre profissionais de saúde e a mulher em abortamento incompleto: "o olhar da mulher". Rev. bras. saúde matern. infant 2005; 5(2):219-228.

29. M ariutti M G, Almeida AM d, Panobianco M S. N ursing care according to women in abortion situations. Rev. Latino-Am. Enfermagem 2007; 15(1):2026.

30. Bertolani GBM, Oliveira EM d. Mulheres em situação de abortamento: estudo de caso. Saúde e Sociedade 2010; 19(2):286-301.

31. Carneiro M. Largada sozinha, mas tudo bem: paradoxos da experiência de mulheres na hospitalização por aborto em Salvador, Bahia [dissertação]. Salvador (BA): Universidade Federal da Bahia; 2012.

32. Costa AM. Integralidade na atenção e no cuidado a saúde. Saúde e Sociedade 2004; 13(3):5-15. 
33. Bazotti KDV, Stumm EM F, Kirchner RM. Ser cuidada por profissionais da saúde: percepções e sentimentos de mulheres que sofreram abortamento. Texto \& Contexto - Enfermagem 2009; 18(1):147-154.

34. Aguiar JM d, d'Oliveira AFPL. Violência institucional em maternidades públicas sob a ótica das usuárias. Interface Comun Saúde Educ 2011; 15(36):79-92.

35. d'Oliveira AF, Diniz SG, Schraiber LB. Violence against women in health-care institutions: an emerging problem. Lancet. 2002; 359(9318):1681-1685.

36. Adesse L. Assistência à mulher em abortamento: a necessária revisão de práticas de má conduta, preconceito e abuso. In: Deslandes S, editor. Humanização dos cuidados em saúde: conceitos, dilemas e práticas. Rio de Janeiro: Ed. Fiocruz; 2006. p. 371387.

37. Samico I, Hartz ZM dA, Felisberto E, Carvalho EFd. Atenção à saúde da criança: uma análise do grau de implantação e da satisfação de profissionais e usuários em dois municípios do estado de Pernambuco, Brasil. Rev. bras. saúde matern. infant 2005; 5(2):229-240.

Artigo apresentado em 10/04/2012

Versão final apresentada em 10/04/2012 